Article available at http://wWw.parasite-journal.org or nitp://dx.dol.org/10.1051/parasite/1995022173

\title{
A NEW ZOONOSIS OF THE CEREBROSPINAL FLUID OF MAN probably Caused by Meningonema peruzZII, A filaria of the CENTRAL NeRVOUS SyStem OF CERCopithecidae
}

\author{
BOUSSINESQ M.*, BAIN O.***, CHABAUD A.G.**, GARDON-WENDEL N.*, KAMGNO J.** \& CHIPPAUX J.P.***
}

\section{Summary:}

A female fourth stage larva of Meningonema, probably of $M$. peruzzii Orihel et Esslinger, 1973, was recovered in Cameroon, from the cerebrospinal fluid of a patient harbouring Loa loa, but without any neurological signs. This observation is the first human case of Meningonema (Filarioidea Splendidofilariinae) which usually parasitizes the central nervous system of African Cercopithecinae. However, as indicated by Orihel and Esslinger, it seems probable that the perstans- like microfilariae described in cases of cerebral filariasis in Zimbabwe belonged to the same species

KEY WORDS : zoonosis. Meningonema peruzzii. Splendidofilariinae. cerebrospinal fluid. Cameroon.

MOTS CLÉS : zoonose. Meningonema peruzzii. Splendidofilariinae. LCR. Cameroun.

\section{INTRODUCTION}

tudies aiming at assessing the prevalence of side effects in patients infected with Loa loa and treated with ivermectin have been carried out in Cameroon for several years (Chippaux et al., 1992). One such study conducted in Central Hospital, Yaounde, demonstrated that microfilariae $(\mathrm{mf})$ of $\mathrm{Loa}$ loa can be found 3-4 days after ivermectin treatment in the cerebrospinal fluid (CSF) of patients harbouring initially high Loa loa microfilarial loads in their blood (Chippaux et al., 1994). These results led us to undertake a study aimed at comparing the Loa loa $\mathrm{mf}$ loads before and three days after ivermectin treatment in the CSF of patients with high microfilaraemia of Loa loa before treatment. Eleven adult volunteers were involved in the study. A nematode macroscopically visible was found in the CSF obtained during the pretreatment lumbar puncture of one of the patients. This parasite is described in the present paper.

\footnotetext{
* Antenne ORSTOM auprès du Centre Pasteur, BP 1274, Yaoundé, Cameroun.

** Laboratoire de Biologie parasitaire, CNRS URA 114, Museum National d'Histoire Naturelle, 61 rue Buffon, F-75231 Paris cedex.

*** CERMES, Niamey, Niger
}

Résumé : LA MÉNINGONÉMOSE, NOUVELLE ZOONOSE FILARIENNE DU LIQUIDE CÉPHALORACHIDIEN DE L'HOMME, DUE PROBABLEMENT À MENINGONEMA PERUZZI, PARASITE DU SYSTÉME NERVEUX CENTRAL DES CERCOPITHECIDAF

Un $4^{e}$ stade larvaire femelle de Meningonema, probablement de M. peruzzii Orihel et Esslinger, 1973, a été récolté, au Cameroun, dans le liquide céphalorachidien d'un malade, porteur de Loa loa, mais n'ayant aucun trouble neurologique. Cette observation constitue le premier cas humain de Meningonema (Filaire Splendidofilariinae) qui est normalement parasite des méninges des Singes Cercopithecinae. Cependant il est probable, ainsi qu'il a été indiqué par Orihel et Esslinger, que les microfilaires de type perstans décrites dans des cas d'encéphalite cérébrale au Zimbabwe puissent être rattachées à cette espèce.

\section{CASE REPORT}

he patient, Mr ATA..., is a 46 year old farmer, belonging to the Eton ethnic group. He lives in Nkolfep, a village located about $20 \mathrm{~km}$ north of the town of Yaounde in an area of degraded forest. He had not received any filaricide treatment during the five previous years.

The study patients were selected according to age, state of health, and the results of skin and blood $\mathrm{mf}$ counts. One standardized thick blood smear was made between 10 a.m. and 4 p.m., using $30 \mu \mathrm{l}$ of blood taken by capillary from a fingerprick, and the blood smear was stained with Giemsa's stain. All mf were counted under a low power microscope. Two skin snips (one at each iliac crest) were taken with a $1.5 \mathrm{~mm}$ Holth corneoscleral punch, and immediately placed in saline. After incubation for 24 hours, the emerged $\mathrm{mf}$ were counted under a microscope.

Patients eligible for the study and who signed an informed consent form, were hospitalized in the Department of Medicine of the Central Hospital in Yaounde.

Venous blood was obtained before ivermectin treatment from all patients for haematological and biochemical examinations comprising complete blood cell counts, protein electrophoresis, and determination of plasma electrolytes, glucose, creatinin, proteins, trans- 


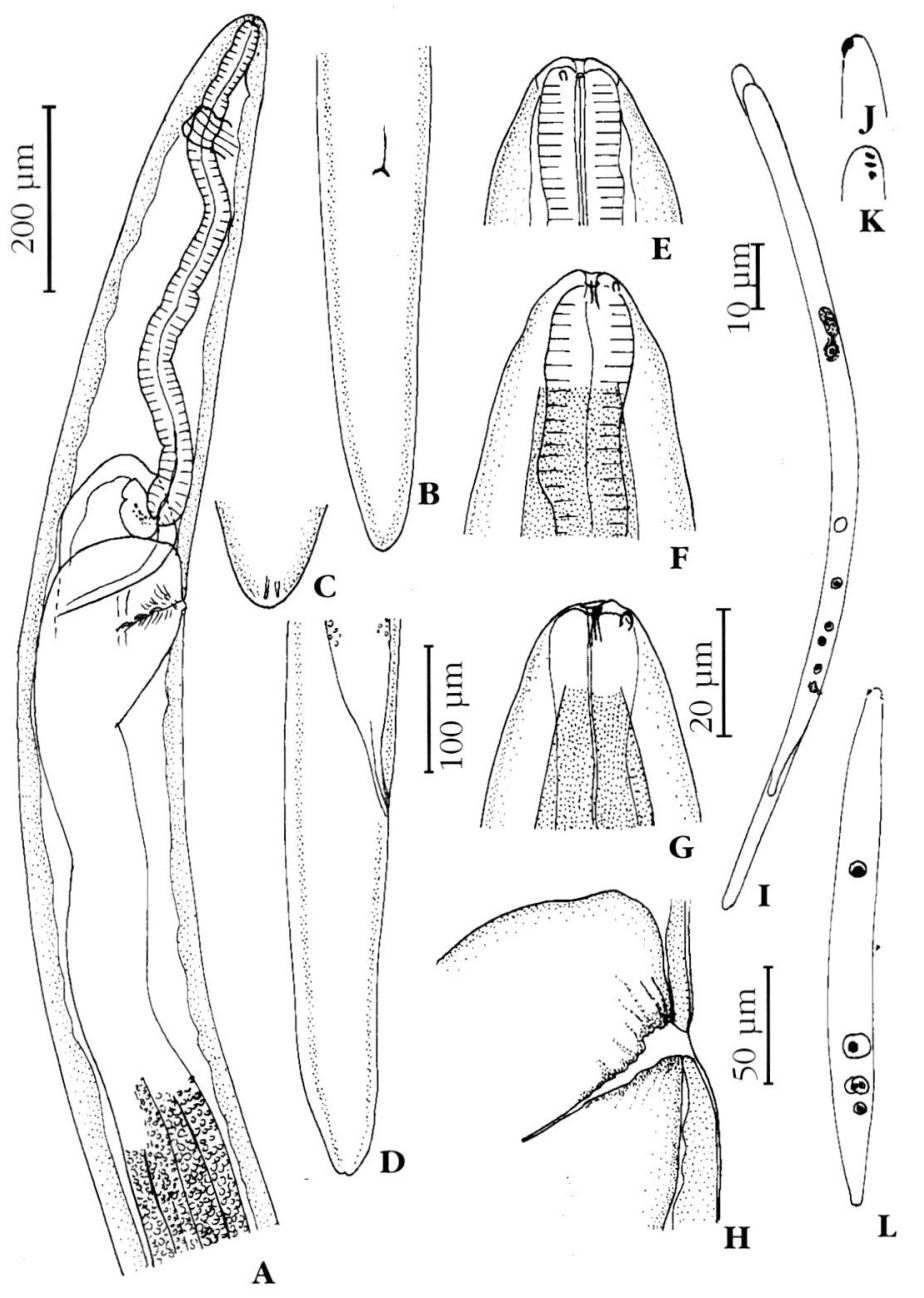

Fig. 2. - Meningonema peruzzii.

Adults from the meninges of a talapoin from Gabon.

A : male, posterior extremity, ventral view. B-E : head of the female, B: lateral view. C : median view. D : id, optical section. E : en face view $\mathrm{F}:$ transversal sections of the buccal cavity from apex to oesophagus. Scales : A : $100 \mu \mathrm{m}$; B,C,D,E : $50 \mu \mathrm{m}$; F : $30 \mu \mathrm{m}$.
Fig. 1. - Meningonema peruzzii

A-H : female, fourth stage larva from cerebrospinal fluid of the patient. A : anterior extremity, lateral view. B : posterior extremity, ventral view. $\mathrm{C}$ : tip of the tail, dorsal view. D : posterior extremity, lateral view. E, F, G, head, median, left lateral and right lateral views. H: vulva, lateral view.

I-L : larvae from talapoin (Gabon). I : microfilaria from uterus. $\mathrm{J}$ : head, dorsal view. $\mathrm{K}$ : head, right lateral view. L : first stage larva from the thoracic muscles of Culicoides nubeculosus, 4 days post infestation.

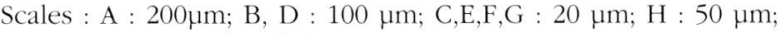
$\mathrm{I}, \mathrm{L}: 10 \mu \mathrm{m} ; \mathrm{J}, \mathrm{K}$ : hand-drawings.

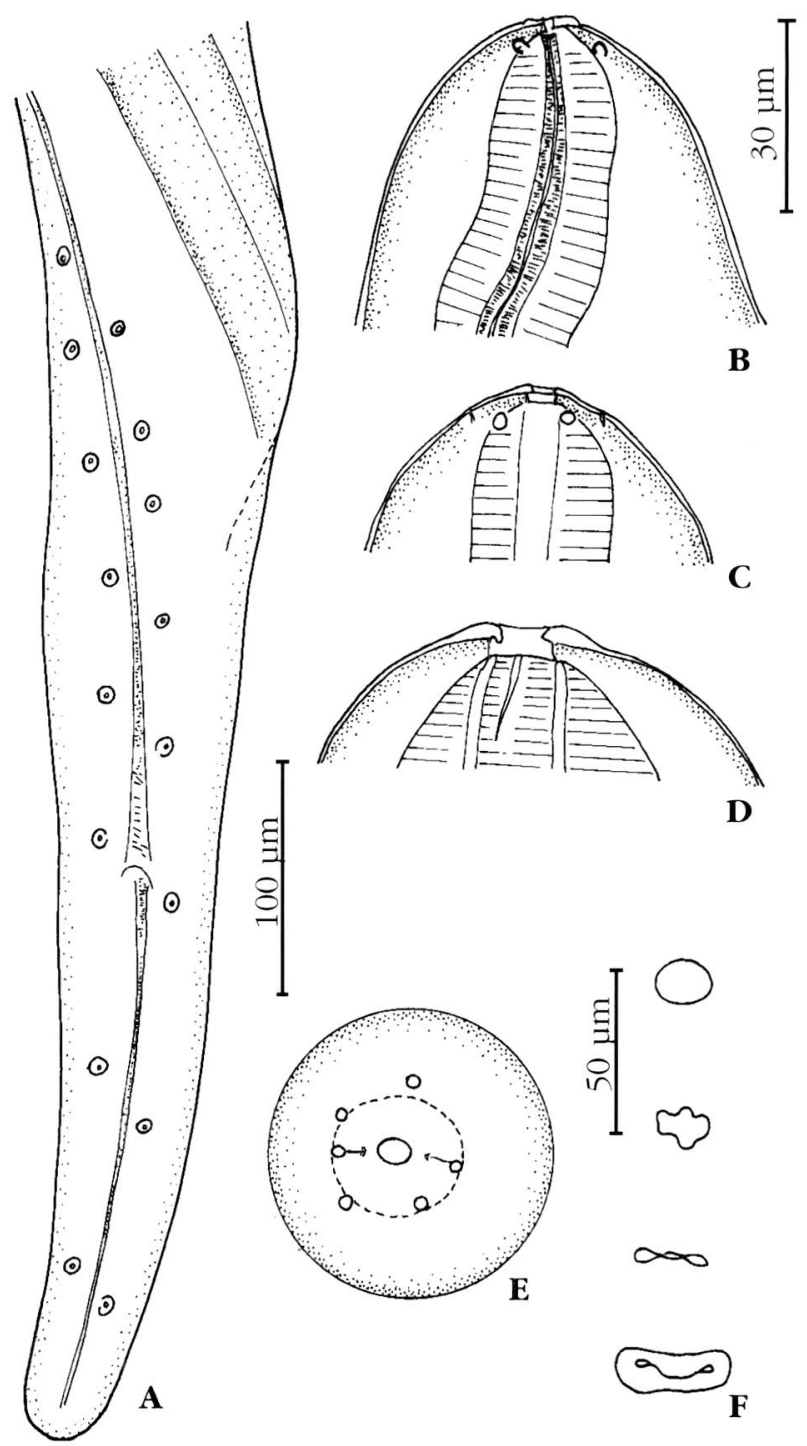


aminases (SGOT and SGPT) and $\mathrm{C}$ reactive protein (CRP). The pretreatment lumbar puncture was performed after a fundus examination. Biochemical, cytological, bacteriological, and parasitological examinations were carried out on the collected CSF.

Three $\mathrm{ml}$ of CSF (one $\mathrm{ml}$ in each of three tubes) were collected from Mr ATA... The CSF was quite clear. Examination of one of the tubes revealed the presence of a mobile nematode measuring $8.7 \mathrm{~mm}$ long. The two other tubes were sent to laboratories of Centre Pasteur, Yaounde, in order to perform standard examinations. The collected nematode was fixed in hot ethanol (70\%) and preserved in the MNHN collection Paris, $\mathrm{n}^{\circ} 179$ HS. No ivermectin treatment was given to Mr ATA...

Mr ATA... did not complain of any neurological symptoms, nor did the clinical examinations reveal any neurological signs.

The patient harboured 1903 Loa loa mf per 30ul blood, and no Mansonella perstans mf. Only one Onchocerca volvulus $\mathrm{mf}$ was recovered from the two skin snips.

Haematological examinations showed only high eosinophil counts ( 630 per $\mu 1$, corresponding to $7.8 \%$ of the leucocytes), low haematocrit (36.8\%), and a microcytosis (red cell corpuscular volume : $66.9 \mathrm{fl}$ ). Blood biochemical parameters were normal, except a slight increase of plasma proteins $(89 \mathrm{~g} / 1)$ and of $\mathrm{C}$ reactive protein $(9.9 \mathrm{mg} / \mathrm{l})$.

All biochemical and cytobacteriological examinations of CSF were normal (308 red cell/mm3; leucocyte counts : $<1$ per mm3; no bacteria after direct examination and after culture).

No mf was found in the CSF.

\section{IDENTIFICATION OF SPECIMEN}

he nematode recovered from the CSF was not, as expected, Loa loa. The specimen is a female fourth stage larva (vulva closed, genital tracts appearing as a solid cord) and can be easily identified as belonging to the genus Meningonema Orihel et Esslinger, 1973 (Splendidofilariinae) on the base of the following characters : presence of four uteri, cuticle smooth and thin, muscular body wall very thin, large pseudocoel, tail long, rounded and without lappets. (Fig.1).

The measurements are the following : body length $8.7 \mathrm{~mm}$, maximum width in the anterior region 180 $\mu \mathrm{m}$, nervous ring at $150 \mu \mathrm{m}$ from apex, buccal cavity $6 \mu \mathrm{m}$ long, oesophagus $600 \mu \mathrm{m}$ long, vulva at $680 \mu \mathrm{m}$ from apex, impaired ovijector $600 \mu \mathrm{m}$ long, tail 300 $\mu \mathrm{m}$ long.

\section{DISCUSSION}

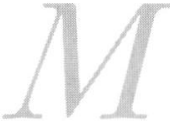

eningonema peruzzii Orihel et Esslinger, 1973 , is the only species described at present in the genus. This parasite has been found in the central nervous system of the Cercopithecidae Cercopithecus (Miopithecus) talapoin in Equatorial Guinea, and was recovered again in the same host in Gabon (see below). As suggested by Orihel and Esslinger, this filaria seems to be the same as that found in 1928 by Peruzzi in a Cercopithecus sp. trapped in Uganda. As the filaria we recovered from the CSF of a Cameroonian individual was a 4 th stage larva, it is impossible to warrant the identification at the specific level. However, the similarity of some unusual characters, such as the presence of an oesophago-intestinal torsion, strongly suggests that the filaria found in Cameroon is the same than those previously recovered from monkeys.

One Miopithecus talapoin which was maintained at the CNRS Biology Station of Makokou (Gabon) and was found to harbour Hepatocystis and sheathed microfilariae, has been splenectomized on 16.07.1976 and shipped by Professor Irène Landau to the MNHN Laboratory in Paris.

The talapoin monkey from Gabon was necropsied on 07.12.1976, and two adult females and one adult male of $M$. peruzzii were recovered from the peribulbar meningeal spaces ( $\mathrm{n}^{\circ} 231 \mathrm{JE}$ MNHN collection. Paris). The specimens showed the same characters than those reported in the original description. Additional morphological data on the male's cloacal papillae and the cephalic structures are given in Figure 2 : eight pairs of cloacal papillae can be seen in ventral view, the left papillae being located more posteriorly. The mouth, the buccal cavity, and the oesophageal lumen are stretched on the lateral plane. The buccal cavity, $5 \mu \mathrm{m}$ long, is constricted halfway by an internal undulating edge. The cuticle of oesophagus is thick and swollen in the median plane. The four cephalic papillae are only slightly prominent and irregularly arranged.

Two microfilariae (from blood and stained with Meldolan blue) were $135-138 \mu \mathrm{m}$ long and $4 \mu \mathrm{m}$ wide; excretory cell, inner body, R1 cell and anal pore respectively at 55-50 $\mu \mathrm{m}, 85-82 \mu \mathrm{m}, 98-93 \mu \mathrm{m}$ and $115-113 \mu \mathrm{m}$ from apex. Head with a hook on the left side and three cuticular points on the right side.

Among the Splendidofilariinae, Meningonema is one of the few genera which was found to parasitize mammals, whereas the other ones are parasites of birds and reptiles. Splendidofilariinae are more often transmitted by Ceratopogonidae than by Culicidae. A 
number of Culicoides nubeculosus, C. variepennis and Aedes aegypti were allowed to get blood meals from the talapoin monkey from Gabon in September and November 1976. No development of filariae was found in the two latter species. In C. nubeculosus six of the 20 dissected females were positive up to the 9th day post engorgement, and some larvae showed a beginning of development in the thoracic muscles. One of these larvae was $95 \mu \mathrm{m}$ long, $8 \mu \mathrm{m}$ wide; R1 cell was enlarged (Fig. 1K). None reached the 2nd larval stage.

The identification, certain at the level of genus, and probable at the level of species, of Meningonema peruzzii from a human, reveals the existence of a new zoonosis. The fact that this species may, indeed, parasitize humans was already suspected by Orihel and Esslinger when they described the parasite recovered from talapoin monkeys. Based on the clinical observations and the description of microfilariae reported by Dukes et al. (1968), Orihel and Esslinger (1973) and Orihel (1973) pointed out that the M. perstans-like microfilariae recovered from patients with cerebral filariasis in Zimbabwe seemed to correspond to $\mathrm{mf}$ of Meningonema and not to M. perstans.

The presence of this species has been demonstrated in Cameroon, Gabon, and Equatorial Guinea, three contiguous countries of Central Africa. It is difficult at present to affirm that the same species exists in more southerly countries. However, this possibility may be supported by the description, in Zimbabwe, of $\mathrm{mf}$ which, though resembling those of $M$. perstans, have been distinguished from the latter by the presence of a sheath and of an elongated caudal nucleus.

At present, the prevalence of the zoonosis cannot be evaluated owing to the fact that Meningonema $\mathrm{mf}$ can be readily confused with those of $M$. perstans, and therefore may escape notice. Moreover, although numerous $\mathrm{mf}$ have been observed in the blood of monkeys parasitized with Meningonema, there is no evidence that $\mathrm{mf}$ of this species are found in the blood of humans. In the proven human case described here no Meningonema $\mathrm{mf}$ were found on the blood smear, possibly due to the fact that the recovered female was not mature. In the two other probable cases reported in Zimbabwe, although $\mathrm{mf}$ were recovered in the CSF, they were also not observed in the blood of the patients. Chambon (1933) has also reported the presence of $\mathrm{mf}$ in the CSF of one patient from Nguele Bengono (Cameroon). This author considered they were $M$. perstans $\mathrm{mf}$. As the patient harboured blood $\mathrm{mf}$, Chambon suggested that meningeal lesions due to trypanosomiasis may have allowed blood $\mathrm{mf}$ to enter in CSF, an hypothesis which may be considered as plausible.
In conclusion, careful examinations of blood smears with $\mathrm{mf}$ resembling $M$. perstans might reveal that Meningonema infection is a relatively frequent zoOnosis. Alternatively, $\mathrm{mf}$ of this species might not be able to reach human blood, and the direct diagnostic of this infection in human might only be possible from examination for $\mathrm{mf}$ in the CSF.

\section{ACKNOWLEDGEMENTS}

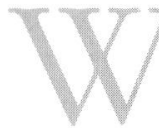

e are very much indebted to Dr. J. E. Bradley for revising the manuscript. We are grateful to Pr. C. E. Ndjitoyap, Dr. W. Ndong, Dr. M. Ducorps and the staff of the Department of Medicine, Central Hospital, Yaoundé, whose invaluable support enabled us to performs the study. We gratefully acknowledge the patients who participated to the trial. We wish to thank the Cameroonian Minister of Public Health for providing his ethical clearance for the study.

This work was supported by the UNDP/World Bank/WHO Special Programme for Research and Training in Tropical Diseases (project 930585).

\section{REFERENCES}

Chambon M. Présence de microfilaires dans le liquide céphalorachidien d'un trypanosomé avancé. Bulletin de la Société de Pathologie Exotique, 1933, 26, 613-614.

Chippaux J.P., ERnould J.C., Gardon J., Gardon-Wendel N., ChANDRE F. \& BARBERI N. Ivermectin treatment of loiasis. Transactions of the Royal Society of Tropical Medicine and Hygiene, 1992, 86, 289-293.

Chippaux J.P., Ducorps M., Ranque S., Gardon N., Boussinesq M., Ndong W., Fobi G., Schneider D., Cot S. \& GARCIA A. Adverse reactions following ivermectin treatment in patients with high Loa loa parasitaemia. American Journal of Tropical Medicine and Hygiene, 1994, 51, 132-134.

Dukes D.C., Gelfand M., Gadd K.G., Clarke V. de V. \& GolDsmid J.M. Cerebral filariasis caused by Acanthocheilonema perstans. The Central African Journal of Medicine, 1966, 14, 21-27.

OriHel T.C. Cerebral filariasis in Rhodesia- a zoonotic infection ? The American Journal of Tropical Medicine and Hygiene, 1973, 22, 596-599.

Orihel T.C. \& Esslinger J.H. Meningonema peruzzii gen. et sp. n. (Nematoda : Filarioidea) from the central nervous system of African monkeys. Journal of Parasitology, 1973, 59, 437-441.

Peruzzi M. Cerebral filariasis in five monkeys infected with trypanosomal meningo-encephalitis. League of Nations Health Organisation. Final report of the International Commission on human trypanosomiasis. 1928, p. 309313. 